\title{
CSN-LAUSD Network: A Dense Accelerometer Network in Los Angeles Schools
}

\section{by Robert W. Clayton, Monica Kohler, Richard Guy, Julian Bunn, Thomas Heaton, and Mani Chandy}

\begin{abstract}
The Community Seismic Network-Los Angeles Unified School District is a network of 300 low-cost microelectromechanical systems accelerometers located in schools in the Los Angeles, California, region. They are capable of accurately recording strong motion up to $\pm 2 g$ and are sufficiently spatially dense that they provide unaliased measurements of strong motions up to $1 \mathrm{~Hz}$ following a major earthquake. They are used to provide state-of-health monitoring for the schools and surrounding communities to guide the emergency response. As a research tool, they can be used to provide estimates of the site response at the schools and, therefore, provide a much denser set of site responses for ground-motion prediction than is currently available.
\end{abstract}

\section{Supplemental Material}

\section{INTRODUCTION}

In this article, we describe a network of 300 accelerometers deployed on campuses of the Los Angeles Unified School District (LAUSD). The network is part of the Community Seismic Network (CSN) (Clayton et al., 2011, 2015) that also has arrays in mid-rise and high-rise buildings in Los Angeles, California, and a dense set of stations on the Jet Propulsion Laboratory in Pasadena, California. As shown in Figure 1, the current CSN-LAUSD deployment spans a 20 by $24 \mathrm{~km}$ area, with an average station spacing of $0.5 \mathrm{~km}$. The CSN-LAUSD network started as a 100-station pilot project in 2015 and has now expanded to 300 stations as of May 2019. The plan is to expand across the entire LAUSD, which is the second-largest school district in the U.S.A. with approximately 1000 campuses spanning a large portion of Los Angeles.

The main purpose of this network is to provide a densely sampled set of strong-motion measurements following a large earthquake. This will help determine the state of health of the schools themselves as well as the surrounding communities and also provide the measurements to determine site responses. The CSN-LAUSD network is intended to be both a research and a production network. It is currently set up to produce measurements of acceleration in continuous and triggered mode for routine monitoring of school infrastructure. However, the platform is flexible enough to allow variations of the basic measurements such as response spectra, to be performed at the sensor level.

There are a few other active networks that also exploit the low-cost sensor technology. The Raspberry Shake network (see Data and Resources) uses geophones and some accelerometers in a worldwide network to detect earthquakes. The MyShake network (Kong et al., 2016), run from University of California Berkeley, uses the accelerometers in smartphones to detect and record local earthquakes, with a goal of providing earthquake early warning in some situations. The P-Alert network in Taiwan (Wu et al., 2016) uses low-cost sensors in schools to provide earthquake early warning and to determine the level of ground shaking.

Deploying in schools provides an excellent mechanism to expand a network across an urban domain. The campuses tend to be relatively evenly distributed across the region and are grouped into districts that often provide a single point of administrative contact. With the CSN, we had tried a number of ideas to expand the network, including volunteer webpages and actively contacting various community groups. While there were some successes with these approaches, in general the efforts produced uneven deployment coverage, and suffered from a dropoff in participation with time. We also tried a school deployment that we based on incorporating the sensors into the educational program. This also was not successful because of the decline in interest after the earth science and earthquake lessons were given, which resulted in a fall-off in the number of active sensors. The method that does seem to be working is to incorporate the sensors into the school infrastructure as part of their safety preparedness program.

The individual stations are autonomous smart sensors that use low-cost accelerometers (microelectromechanical systems [MEMS] devices). They are not as sensitive as traditional seismic networks for weak motions but perform well during strong motions. They are easy to install, usually taking less than an hour per site. The stations send their data to a central facility located in the cloud (currently the Amazon Web Services [AWS]). 
(a)

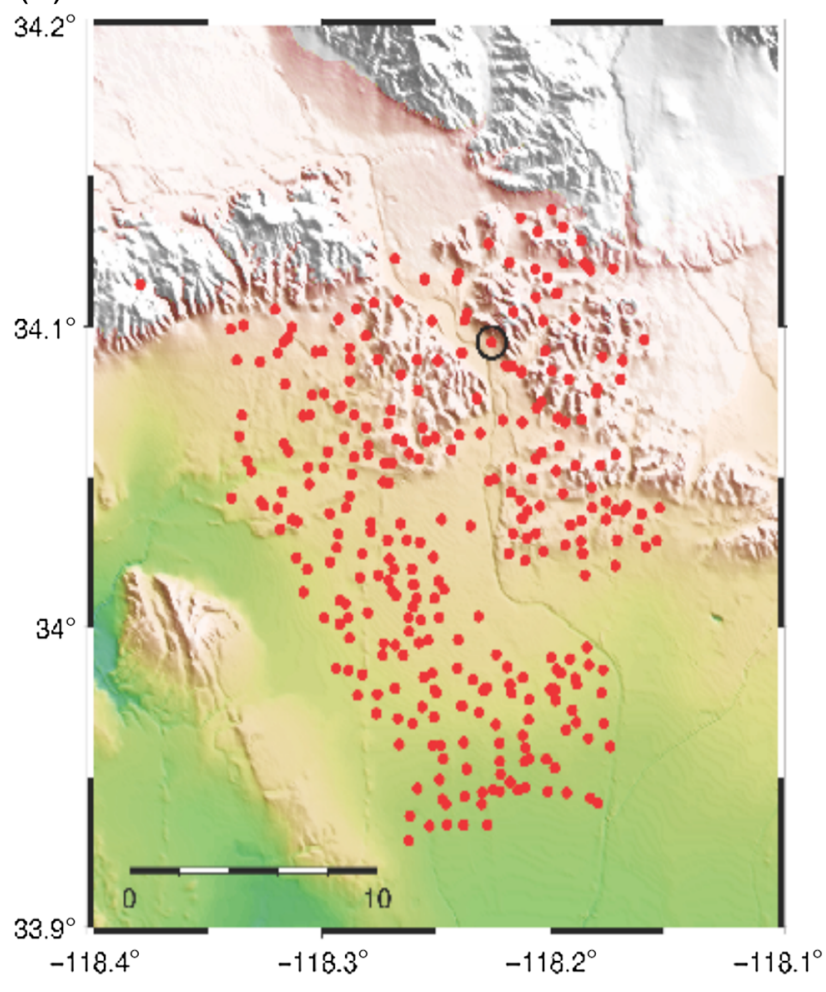

(b)

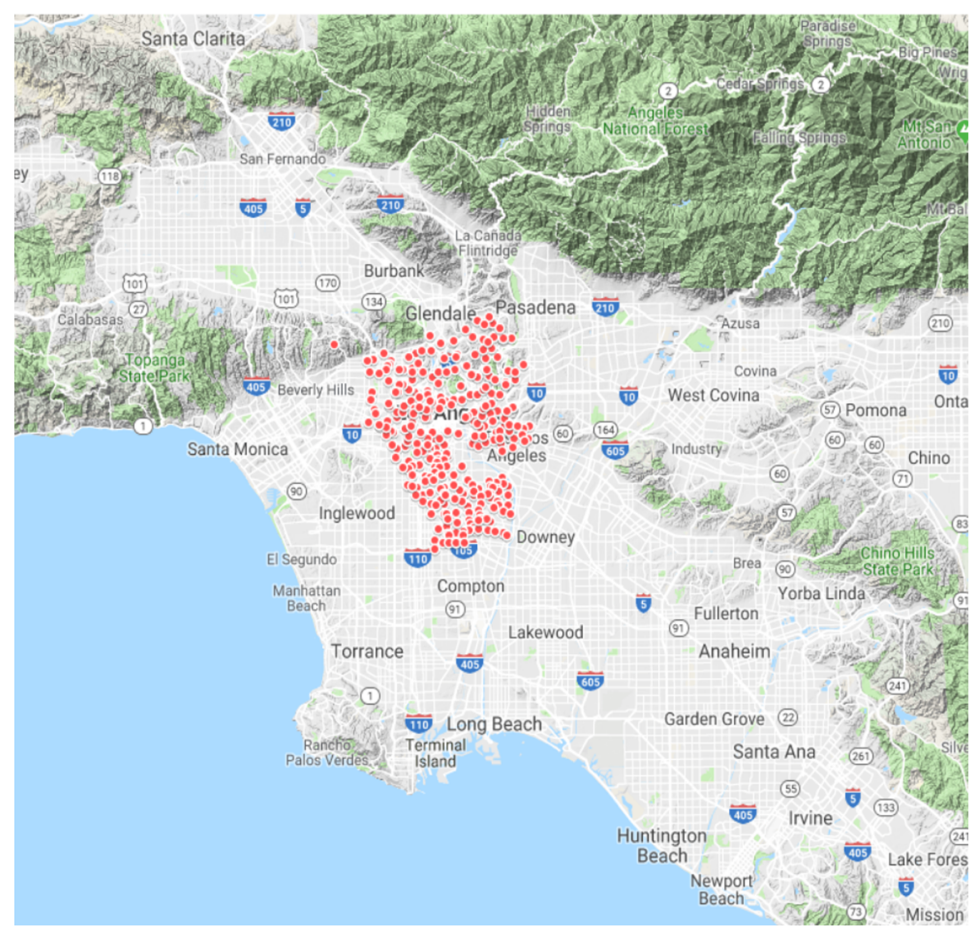

- Figure 1. Location of the Community Seismic Network-Los Angeles Unified School District (CSN-LAUSD) array. (a) The stations on a topographic map with the stations as red dots. The circled station is the one used in Figures 4 and 5. (a) The stations on a Google Map image of the Los Angeles region. The color version of this figure is available only in the electronic edition.

\section{THE SENSOR PACKAGE}

The sensor package is shown in Figure 2 and is the same one used in other CSN stations. It consists of an MEMS accelerometer coupled to a microcomputer, with the host site providing power and an ethernet connection. The only additional equipment is a small Uninterruptible Power Supply system to keep the station alive for a few hours in case of power outage. The entire hardware costs are approximately $\$ 350$ U.S. per station.

The sensor is a three-axis MEMS accelerometer. The one we currently use is an ST-Micro chip (LIS-344LH) packaged as a Phidget 1043 (Phidget), with a sensitivity of $70 \mu \mathrm{g} / \mathrm{sqrt}(\mathrm{Hz})$. It is classified as a class- $\mathrm{C}$ accelerometer and provides 16 bits of resolution on a maximum on-scale range of $\pm 2 g$. The interface to the sensor samples at 1200 samples/s, which we immediately downsample to $50 \mathrm{samples} / \mathrm{s}$ to reduce the data volume, and also to prevent the unit from being used as a microphone. The latter is important for privacy considerations in some locations. The sensor is about four times more sensitive than those in modern cellphones (Faulkner et al., 2014) but significantly less sensitive than observatory-class instruments. The performance of several class-C sensors is documented in Evans et al. (2014), but the most compelling demonstration of performance is the side-by-side comparison of the CSN sensor with an EpiSensor accelerometer (a class A observatory sensor)

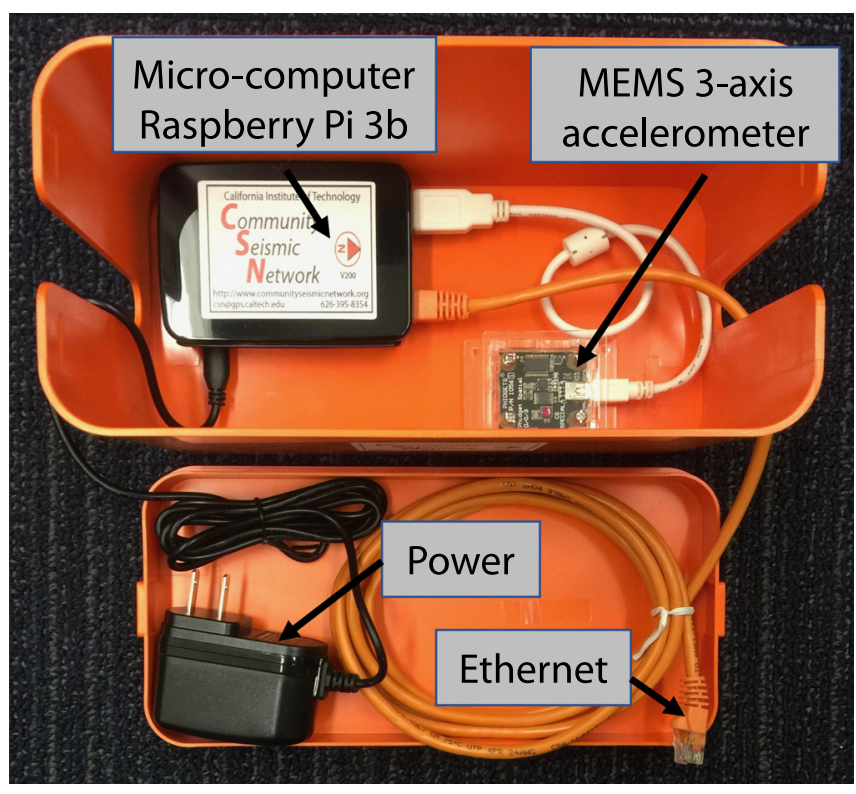

$\Delta$ Figure 2. The CSN Sensor Package. Inside the box the Raspberry-Pi $3 \mathrm{~b}$ and the three-axis microelectromechanical systems (MEMS) sensor can be seen. They are fastened to the box with two-sided adhesive pads. The external connections are to power on the Internet. The color version of this figure is available only in the electronic edition. 


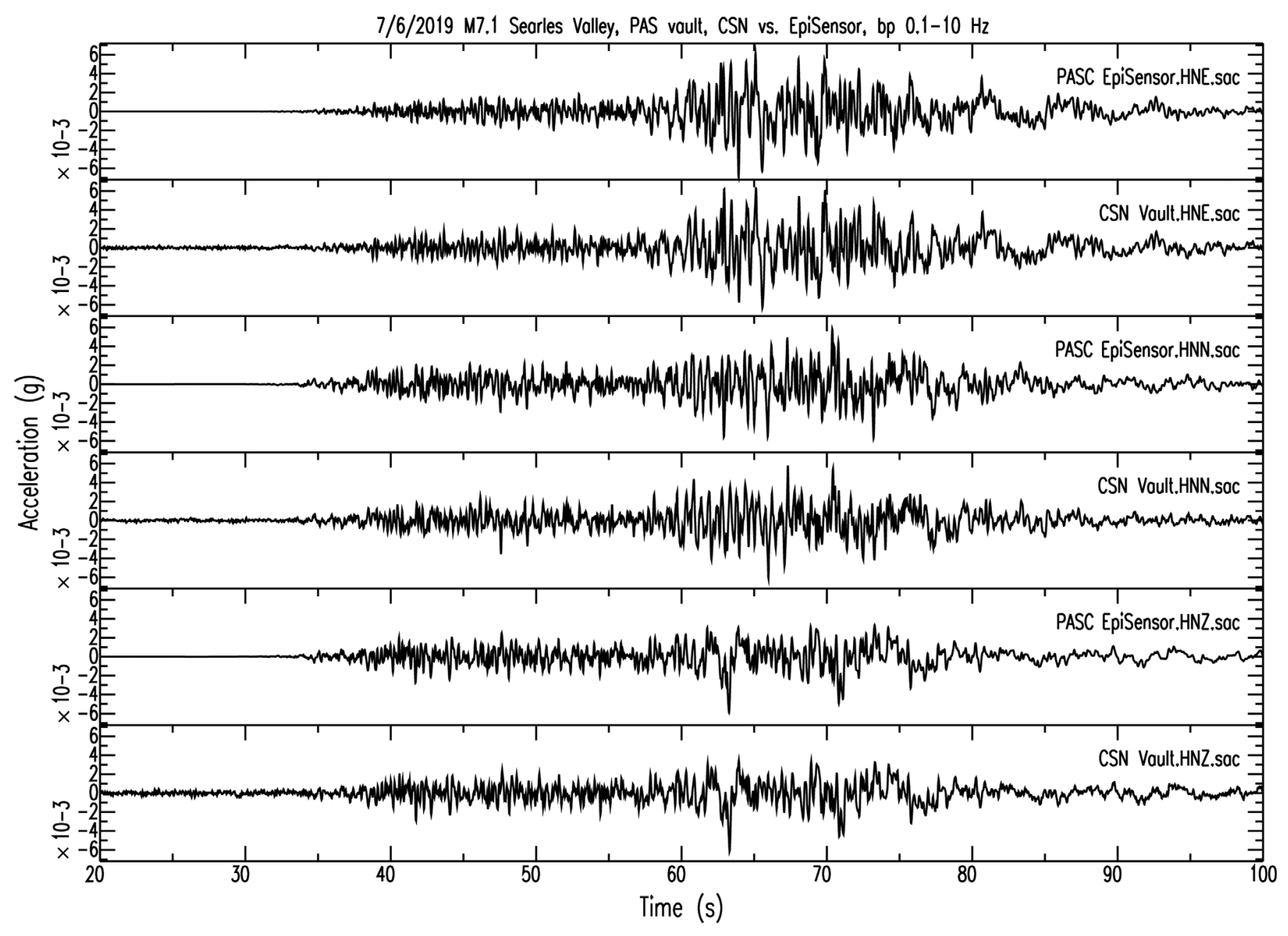

A Figure 3. Comparison of a Phidget and an EpiSensor for the 6 July 2019 M 7.1 Ridgecrest earthquake. The vertical scales for all traces are the same with a maximum of $6 \times 10^{-3} \mathrm{~g}$. The horizontal scale is from 20 to $100 \mathrm{~s}$ after the origin. The sensors are collocated in the vault of the PASC station of the Southern California Seismic Network.

shown for the 6 July 2019 M 7.1 Ridgecrest earthquake in Figure 3. The MEMS device is indistinguishable from the EpiSensor in terms of waveform, amplitude, and timing.

The microcomputer in the sensor package is currently a Raspberry-Pi 3b, which provides sufficient computational power to handle both the routine tasks of the station along with some additional onsite analysis. The processor runs a Linux/Debian operating system, and the station software is written in Python to allow it to be updated quickly and easily (available on GitHub, see Data and Resources). When the computer starts, it opens a reverse-SSH channel to a central computer to allow software updates and operation monitoring. The station automatically restarts after a power interruption, and it has a watchdog program to detect when the system is not functioning due to network failures or other issues. Timing among stations is synchronized by network time protocol (NTP), which provides an accuracy of approximately $0.02 \mathrm{~s}$ (one sample point in the data stream). The stations generally connect to an NTP server located at Caltech but will switch to other servers, if necessary. The microcomputer maintains an http interface, which allows teachers or school administrators to graphically monitor the station using a cellphone or other web-capable devices. This provides a mechanism to incorporate the station into class demonstrations if they desire.

The stations are generally easy to install. They are usually installed in the basement or on the first floor and are placed on a hard floor (usually concrete) near the communications hub for the school, where there is power and Internet access available. They are attached to the surface with two-sided industrial-strength adhesive pads to keep the station fixed to the ground during strong motions. The stations are oriented with a compass. On initial startup, the station registers itself with the cloud and starts recording immediately. Installation takes approximately an hour, and constructing the station packages from component parts is also quick. A group of five can assemble 100 sets in a 1- to 2-hr-time period.

One of the lessons learned in deploying in schools is to put the instruments on their own VPN network within the school communication network. In our case, this was set up and is maintained by the LAUSD technical staff. It allows the seismic 
system to function without interfering with, or without being interfered by, the educational and administrative components of the network. Each station transfers approximately $50 \mathrm{MB}$ of data per day, which appears to have a minimal impact on the school network.

\section{THE NETWORK}

The stations communicate their data to a cloud-based facility that is currently the AWS S3 system. The communication is done in two modes. The continuous data are sent in 10-min chunks that include the starting and ending time stamps. In the cloud, these data are resampled to the 50 samples/s rate to compensate for small variations in the digitization of the MEMS sensor signal. Typically, 0-3 samples of the 30,000 that make up the 10-min chunk are added or removed by the process. This minimizes the clock drift in the system. The continuous waveform segments are then sent to an archiving system housed at Caltech. The data are also retained in the cloud for a week in case it needs to be analyzed from outside the area affected by the earthquake. We are planning to move the permanent archive itself to the cloud and have already moved two years of continuous data to AWS storage.

The second mode of communication is driven by event detection at the station level. The stations monitor the data stream for accelerations that exceed $0.005 \mathrm{~g}(0.5 \% \mathrm{~g})$. This triggers the system, and it sends the maximum acceleration over the next $1 \mathrm{~s}$ to the cloud. This continues until the signal drops below the threshold. These streams of data are then used to create an evolving map of shaking at the schools. The density of the network obviates the need to interpolate. The 1-s window is used in an attempt to push information about the level of shaking to the cloud before the possible collapse of the Internet caused by the event itself. The system continues picking in 1-s windows until the event has passed. Whether the system will provide useful information during a major event has not been tested, but we expect that it will function at least as well as hard-wired networks because in those networks the communication is likely done with the same physical paths and switching centers as the Internet. We use triggers from the Southern California Seismic Network (SCSN) to initiate the analysis of the pick data. The network also contributes to earthquake early warning by providing the picks to the FinDer system (Bose et al., 2012) using an ActiveMQ message broker system running in the AWS. This reduces latency times to under $10 \mathrm{~ms}$, which is usually less than the SCSN network.

\section{DATA}

The data that are sent to the archive facility at Caltech are processed in a fashion similar to the data from the SCSN network. In the LAUSD case, the raw waveform segments are held on a mass-storage device in Seismic Analysis Code binary format because the acceleration data do not significantly compress with the algorithms associated with miniSEED or with zip formats. Approximately $50 \mathrm{MB}$ per station are archived, resulting in a daily intake of $15 \mathrm{~GB}$ for the 300-station LAUSD network. The archive grows at an annual rate of about $6 \mathrm{~TB}$ per year. The archive waveforms are backed up daily on a portable disk.

Each 10-min waveform segment is kept in a database that includes the station name and component, the start and end time, sample rate, and location of the associated waveform. This allows the retrieval system to quickly construct time windows of data across the whole array. The database is currently kept as a flatfile but will be converted to a regular database at some point in the future. A separate station information database is also maintained.

The data are retrieved from the system by an stp interface that is functionally the same as the one used on SCSN. Whenever a significant earthquake is detected on the LAUSD system, a window of the waveform data is created with stp and placed on the data page of the LAUSD network where it can be downloaded by anyone (see Data and Resources for the URL). At the moment, requests for the continuous data are treated on a case-by-case basis due to privacy concerns. The issue is that the seismic sensors are capable of detecting many more activities than just earthquakes. We expect that continuous data from the LAUSD will be made public in the future (possibly with some delay relative to event times).

On a regular basis, we extract several attributes from the data streams. For example, for each 10-min window of data, we extract the signal mean, root mean square, and maximum. Examples of the maximum accelerations for one LAUSD school campus are shown for one day and one year in Figure 4. The activity at the school can be clearly seen both as a daily cycle and over the school year. The obvious anthropological "noise," it is well below any felt earthquake motions at the schools, and generally below the trigger threshold of $0.005 \mathrm{~g}$. At this level, each school produces a few spurious picks per day, which is useful for monitoring the health of the system. Excessive picking is one of the indicators we use to detect problems at a particular site.

\section{EXAMPLE OF THE M 7.1 RIDGECREST EARTHQUAKE}

On 4 July 2019, there was a magnitude 6.4 earthquake in the Ridgecrest area approximately $200 \mathrm{~km}$ north of the LAUSD array. This was followed by a magnitude 7.1 earthquake in the same region. These events, which ended the earthquake drought that had existed in southern California for the past $20 \mathrm{yr}$, were well recorded by the CSN-LAUSD network. An example of the recording is shown in Figure 5. The waveforms show the complicated nature of seismograms recorded in the Los Angeles region, with substantial coda following the $P$ and $S$ waves that are likely caused by scattering. The stations had a peak acceleration of approximately $5 \% \mathrm{~g}$.

Figure 6 shows the response of the whole network to the earthquake. These have been filtered to passbands of 100-1 s and 100-5 s, which show that the sensors are capable of measuring the ground motion that is important to structures. The snapshot of the movies of the motions shows a coherent 
(a)

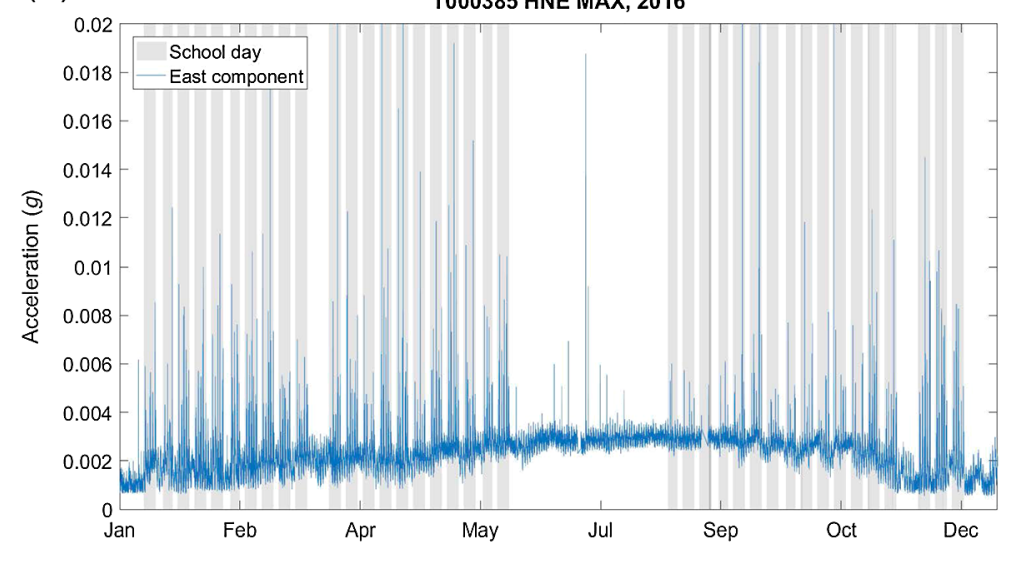

(b)

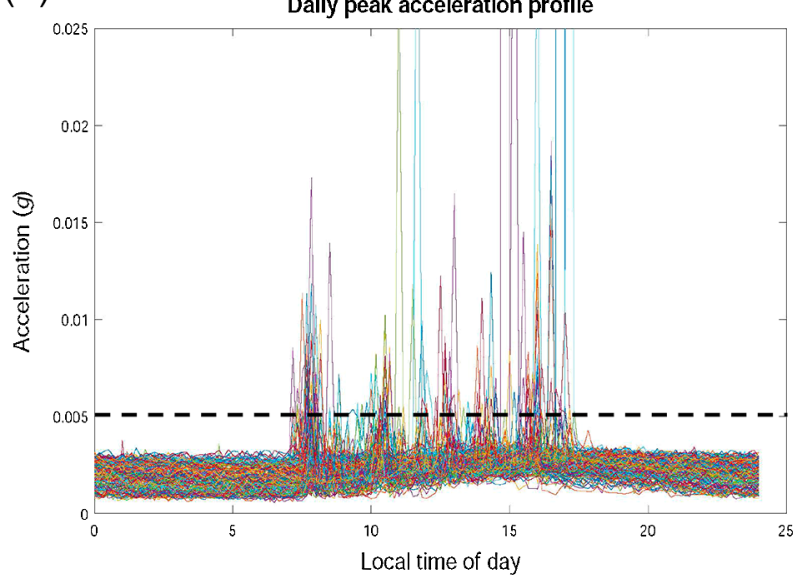

A Figure 4. Measurement histories at one school. (a) The maximum daily acceleration over a year at the school that is marked in Figure 1. The gray bars denote weeks when the school is in session. The base level, which appears as a thick blue line, shows the annual variation in the ambient noise at this site. (b) The peak acceleration in 10 min windows over a day, with a trace for each day in 2016 for the same school. The current trigger level $(0.005 \mathrm{~g})$ is the dashed and shows that this station will trigger a few times per day. The color version of this figure is available only in the electronic edition.

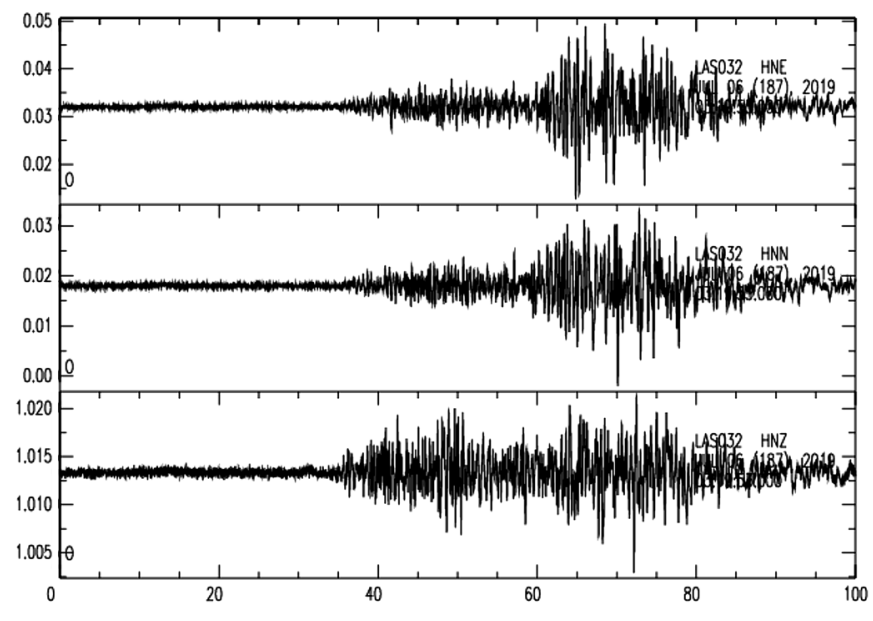

- Figure 5. Recording of the Ridgecrest earthquake at LAS032. The three components of motion (unfiltered) are shown. The location of the station is shown in Figure 1.

wavefront moving across the region along with lateral variations in the local site amplification. The lateral variations are stronger in higher-frequency wavefield in the Los Angeles basin portion of the network. The movies themselves are in the (E) supplementary material.

\section{MICROZONATION AND SITE RESPONSE}

One of the problems of applying ground-motion prediction equation models to individual locations is in determining the local site response. These are generally characterized by $V_{S 30}$, which is the shear-wave velocity in the top $30 \mathrm{~m}$ of the earth. Unfortunately, there are very few direct measurements of $V_{S 30}$, and proxy quantities such as terrain slope (Allen and Wald,
2009) are used to interpolate. For example, in the region shown in Figure 7, there are only $12 V_{S 30}$ measurements (Yong et al., 2016).

The LAUSD@CSN provides an opportunity to produce much more densely sampled site responses. There are several techniques for doing this type of analysis including, spatial autocorrelation, horizontal to vertical spectral ratios (ChavezGarcia and Kiang, 2014), and noise correlation, which we expect to do with the data recorded by the network. In Figure 7, we show the response spectra (Trifunac, 2008) at 1- and 5-s period determined from the Ridgecrest event. The response spectrum is the output of a damped singledegree-of-freedom oscillator driven by the observed accelerations. It is designed to model the response of the fundamental mode of buildings with $1 \mathrm{~s}$ being suitable for 1-10 story structures and $5 \mathrm{~s}$ for 50 -story high-rises. The results for $1 \mathrm{~s}$ show a significant lateral variation across the LAUSD network, which would be difficult to capture with a sparse network. The $5 \mathrm{~s}$ spectral response shows the large amplification due to the Los Angeles basin on the southern half of the network.

\section{STATE OF HEALTH OF THE SCHOOLS}

In addition to producing a map of peak accelerations after a major earthquake, we will provide a tool for assessing damage at each campus. To do this we use the peak acceleration as an input to a fragility curve, which then produces a likelihood estimate that the school has been damaged (Kohler et al., 2018). A simple version of a fragility curve is shown in Figure 8. The peak acceleration measured at the school is input to this curve ( $x$-axis), which translates this to a likelihood of damage at the school. In general, the fragility curves would be custom for each school, but we are initially using one curve for all schools. The 
(a)
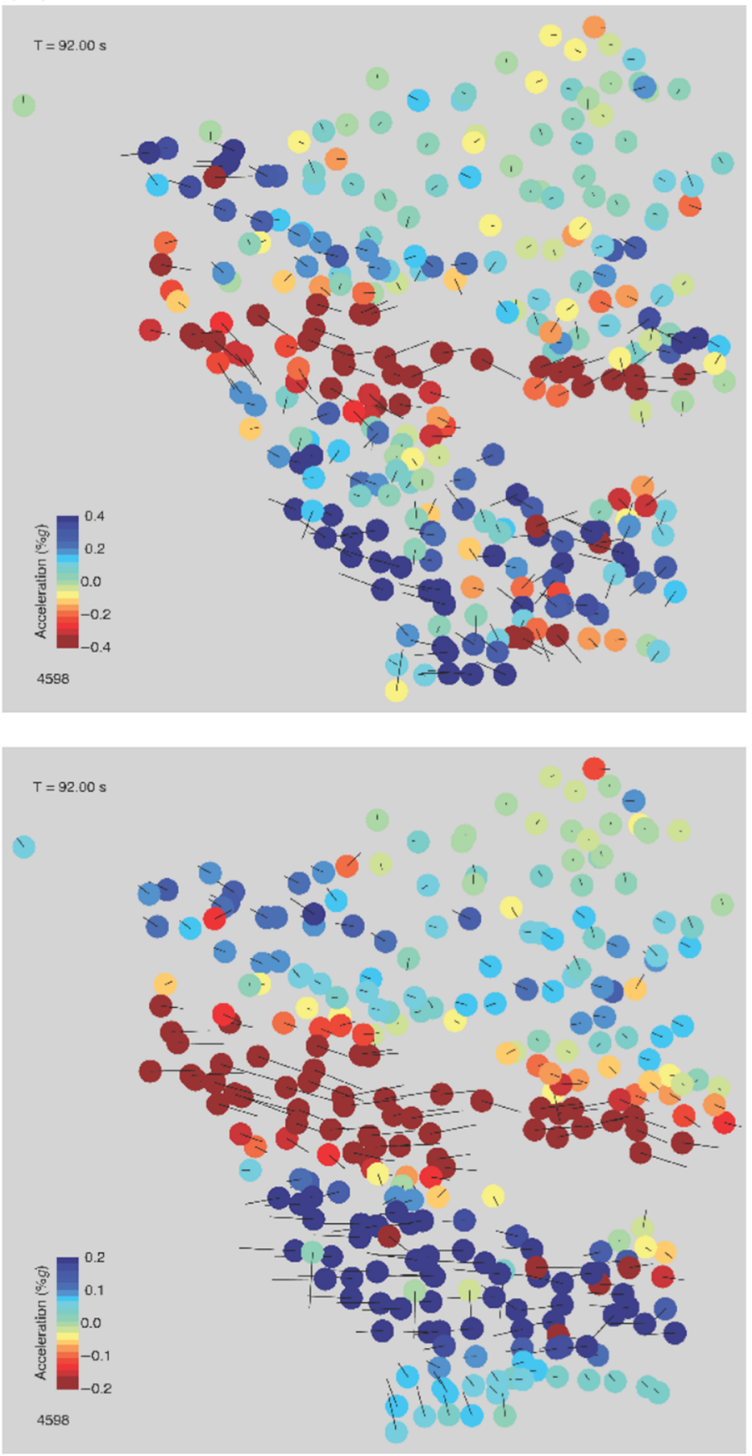

(b)
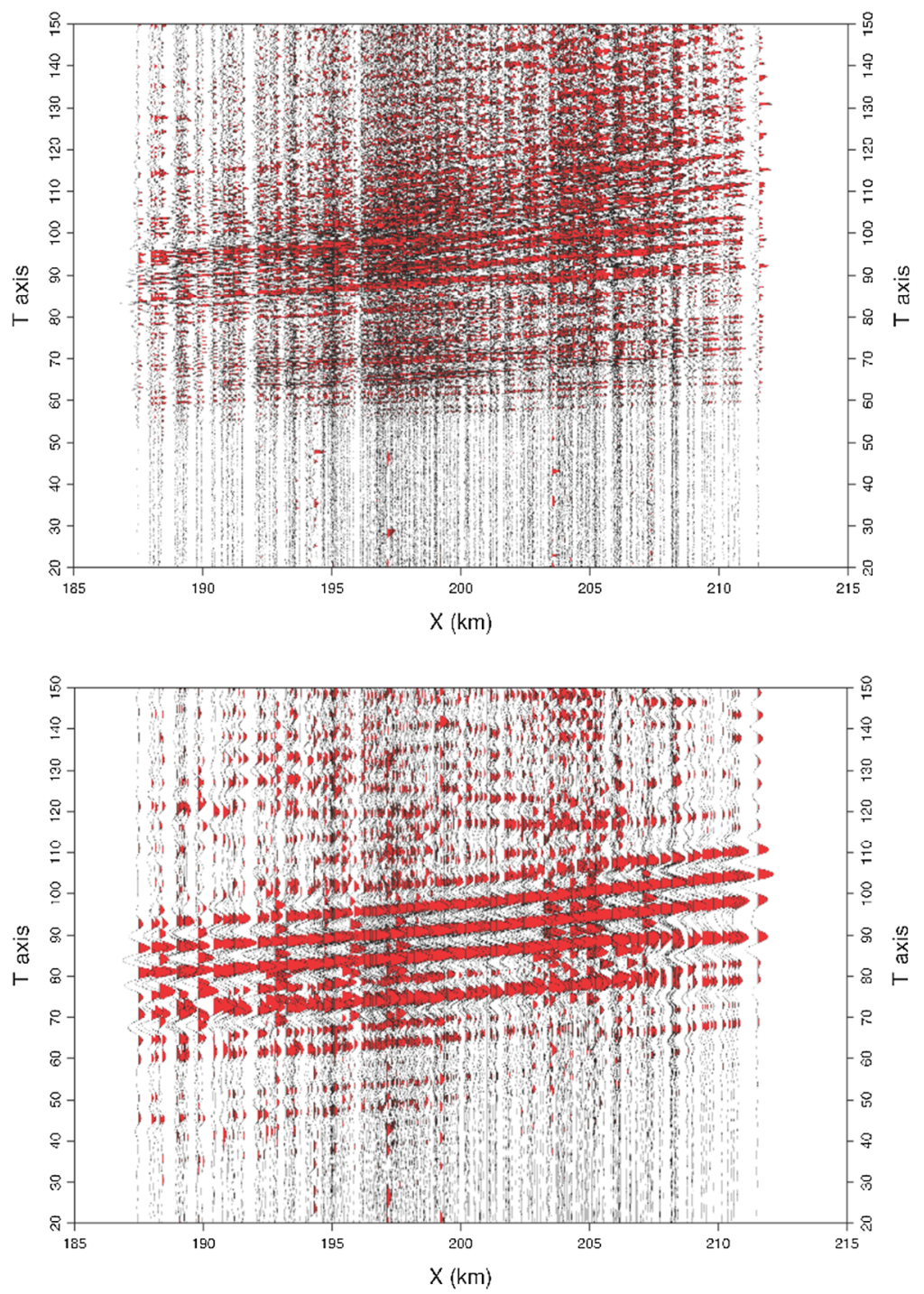

- Figure 6. LAUSD recording of the Ridgecrest earthquake. (a) One frame of movies of the $S$ waves crossing the LAUSD array. The top one is filtered 100-1 s, and the bottom one is filtered 100-5 s. The thin black lines show the direction of particle motion. The full movies are in the (E) supplementary material. The stripes (tilted northwest-southeast) are the main wave crest of the surface waves. (b) The sections sorted by distance, with the same filtering as with (a). The color version of this figure is available only in the electronic edition.

plan is to make these curves for each building, possibly using more information than just peak acceleration.

The state of health display can be viewed from anywhere and is useful for prioritizing the actions for each campus. The results are also important for the general emergency response because the schools are often the evacuation centers. A synthetic example of a state of health display is also shown in Figure 8.

In general, the fragility curves are based on the building design at each school. The LAUSD@CSN network can provide a platform to study other inputs to the fragility analysis such as accelerations and velocities at particular frequencies.
We will then consider models of the individual school structures and look for the input levels that cause exceedance of major structural elements. Having continuous recordings at each of the schools is an important element of this research.

\section{FUTURE PLANS}

Deploying seismic stations in schools provides a road map for covering the entire Los Angeles basin, a region of 16 million inhabitants. The immediate next step is to expand the current system to the entire 1000-campus LAUSD system. This will provide coverage for a significant portion of the city of Los 

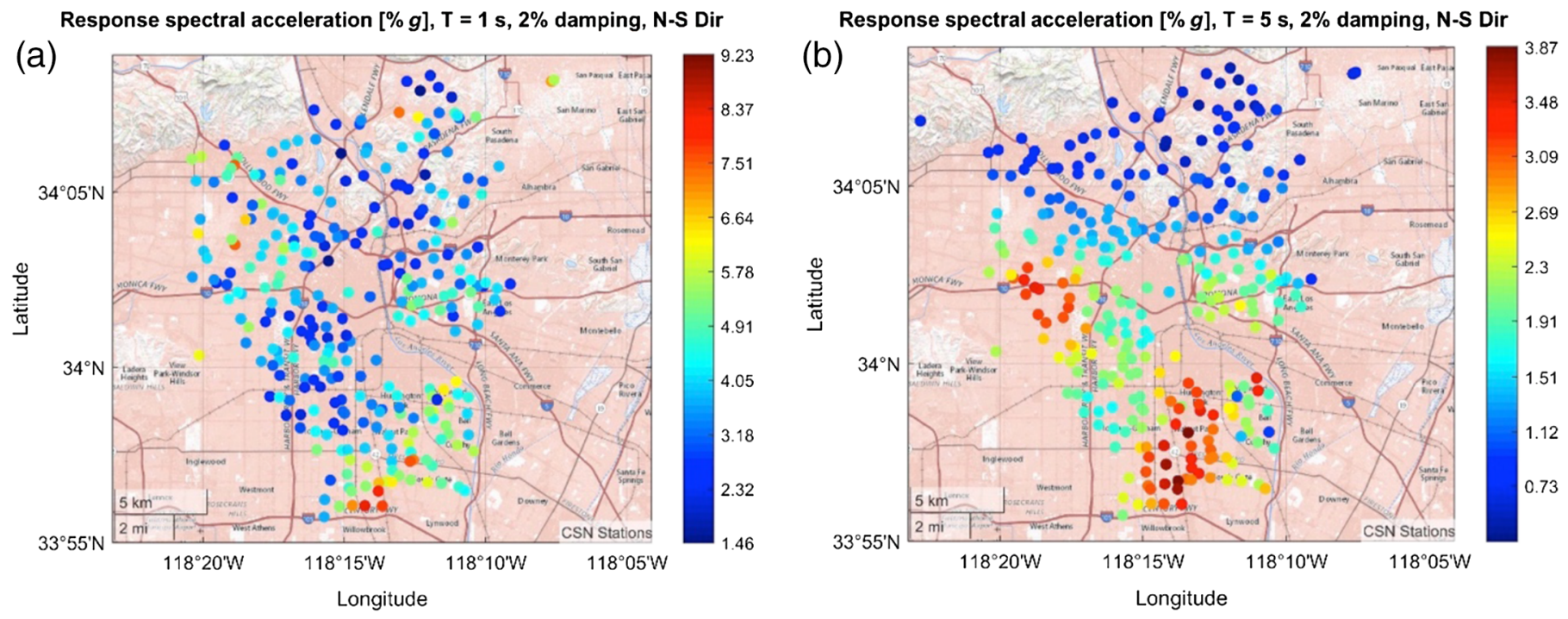

A Figure 7. Response spectra for the Ridgecrest earthquake. (a) The response spectra (output of a single-degree-of-freedom oscillator designed to mimic the fundamental mode of building deformation) for $1 \mathrm{~s}$, which is for $1-10$ story buildings, and for $5 \mathrm{~s}$, which is for 50 -story buildings. (a) The lateral variations in site response across the array, and (b) the effect of the Los Angeles basin. N-S, north-south. The color version of this figure is available only in the electronic edition.

(a) LAUSD building shaking
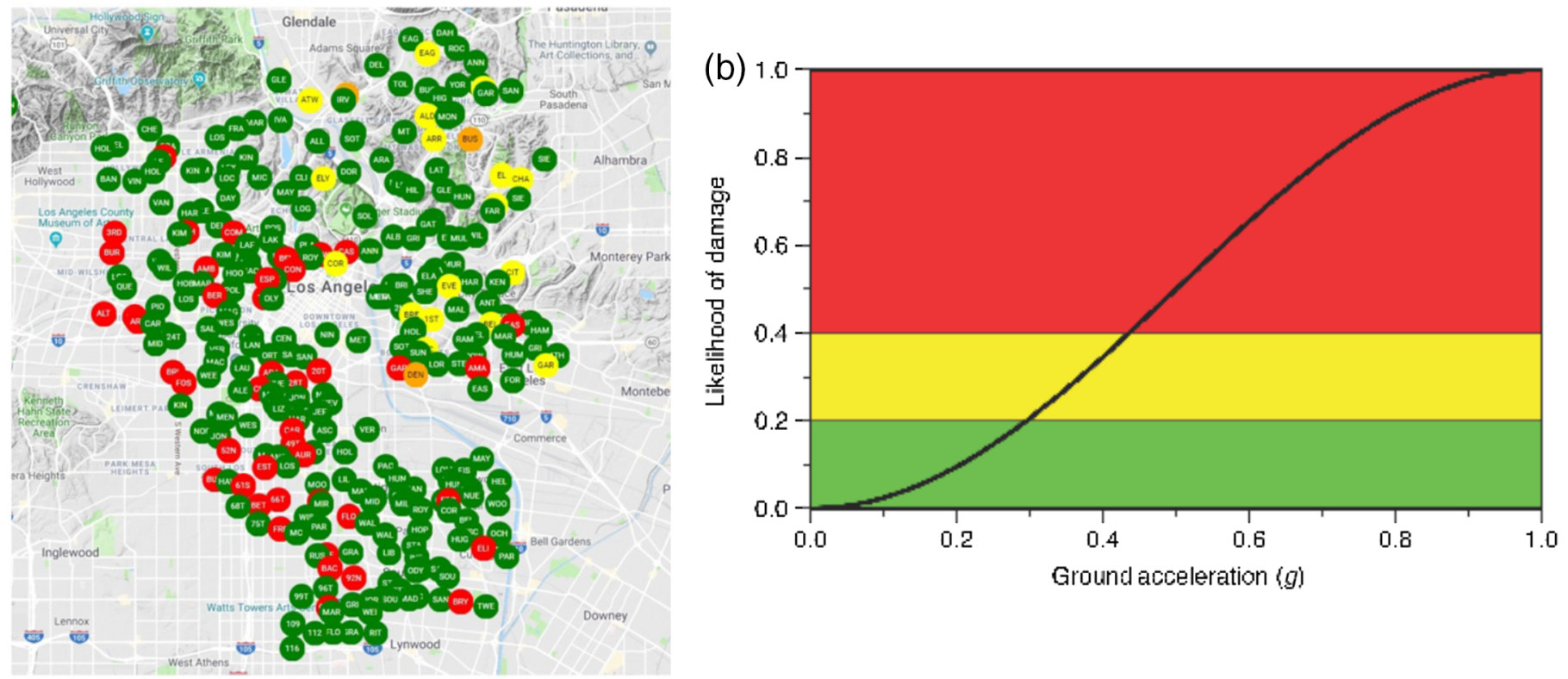

- Figure 8. Sample state of health display. (a) A hypothetical state-of-health warning that would be available shortly following a major earthquake in Los Angeles. The colors indicate alert levels for potential damage to the structures, based on a fragility curve, an example of which is shown in (b). This curve translates peak ground acceleration to likelihood of damage. This is a purely synthetic example as there have not been any earthquakes in the past two decades capable of generating anything but green dots. The color version of this figure is available only in the electronic edition.

Angeles and the San Fernando Valley. The step will necessitate funding but also a change of administrative structure. The plan is to engage other (academic) institutions in running portions of the network that is closest to them.
The plan to locate sensors in schools allows us to locate approximately 4000 sensors in the Los Angeles region as shown in Figure 9. With this breadth and density of the network, we should be able to provide high-resolution maps of strong 


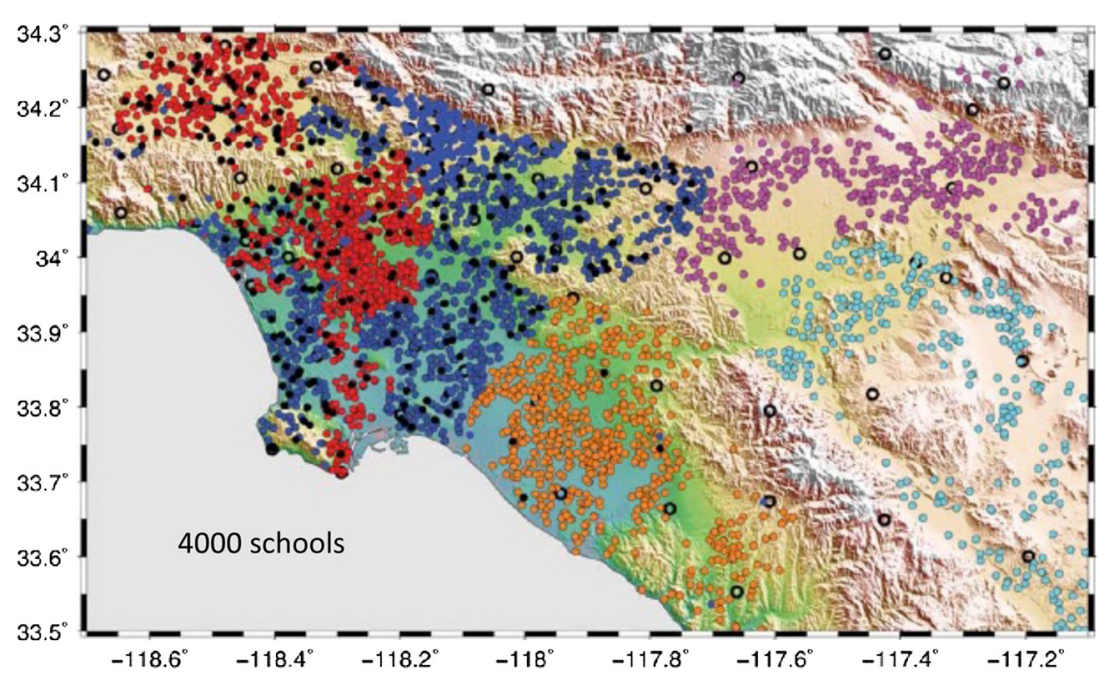

$\Delta$ Figure 9. Expansion Plans. The dots represent various public and private school in the Los Angeles area. There are over 4000 potential sites. The red dots are the LAUSD (1000 schools), the blue are other schools district within Los Angeles county, and the black dots are private schools. The other colored dots are schools in Orange, San Bernardino and Riverside counties. The color version of this figure is available only in the electronic edition.

shaking across this densely populated area. This will be important for prioritizing the response following a major earthquake such as the one used in the ShakeOut exercise (Jones et al., 2008) that simulated widespread damage across the whole region.

\section{DATA AND RESOURCES}

Data from felt and interesting events are available at http:// csn.caltech.edu/data/ along with the recordings of other Community Seismic Network (CSN) stations. In particular the data of the Ridgecrest earthquake shown in Figures 3, 5, 6, 7 and (E) S1 are archived there. The continuous data from the CSN network are not generally released due to privacy concerns, but we are attempting to obtain permission for the Los Angeles Unified School District (LAUSD) stations. The $V_{\mathrm{S} 30}$ measures in the region of LAUSD are available from https:// earthquake.usgs.gov/data/vs30. The client software is available at https://github.com/jjbunn/PyCSN. More information on the CSN and CSN-LAUSD networks is available at http://csn. caltech.edu (last accessed July 27, 2019). The Raspberry Shake network can be accessed at https://raspberryshake.org. Details on the Phidget sensor are available at https://www.phidgets.com/ ?\&prodid=31. All websites were last accessed on July 2019. The (E) supplemental material includes movies of ground accelerations due to the 6 July 2019 M7.1 Ridgecrest earthquake are shown in Figure $S 1$. The time slices shown in Figure 6 are one panel from each of the videos. The data have been bandpass filtered from $100-1 \mathrm{~s}$ and $100-5 \mathrm{~s}$. The movie starts at $60 \mathrm{~s}$ after the origin time and runs until $92 \mathrm{~s} \mathbf{<}$

\section{ACKNOWLEDGMENTS}

The authors thank the Betty and Gordon Moore Foundation, Caltech, the Conrad J. Hilton Foundation, and Computers and Structures, Inc., for funding for this project. The authors thank Los Angeles Unified School District (LAUSD), and in particular Jill Barnes, for facilitating this project, and the many volunteers who have helped build the Community Seismic Network (CSN) sensors. Charles Dorn and Filippos Filippitzis from Caltech created Figures 4 and 7, respectively.

\section{REFERENCES}

Allen, T. I., and D. J. Wald (2009). On the use of highresolution topographic data as a proxy for seismic site conditions (Vs30), Bull. Seismol. Soc. Am. 99, no. 2A, 935-943.

Bose, M., T. Heaton, and E. Hauksson (2012). RealTime Finite Fault Rupture Detector (FinDer) for large earthquakes, Geophys. J. Int. 191, no. 2, 803812.

Chavez-Garcia, F., and T-S. Kiang (2014). Lateral heterogeneities and microtremors: Limitations of HVSR and SPAC studies for site response, Eng. Geol. 174, no. 23, 1-10, doi: 10.1016/j.enggeo.2014.07 .007 .

Clayton, R., T. Heaton, M. Chandy, A. Krause, M. Kohler, J. Bunn, M. Olson, M. Faulkner, M. Cheng, L. Strand, R. Chandy, D. Obenshain, A. Liu, and M. Aivazis (2011). Community Seismic Network, Ann. Geophys. 54, no. 6, doi: 10.4401/ag-5269.

Clayton, R., T. Heaton, M. Kohler, M. Chandy, R. Guy, and J. Bunn (2015). Community seismic network: A dense array to sense earthquake strong motion, Seismol. Res. Lett. 86, no. 5, doi: 10.1785/ 0220150094 .

Evans, J., R. Allen, A. Chung, E. Cochran, R. Guy, M. Hellweg, and J. Lawrence (2014). Performance of several low-cost accelerometers, Seismol. Res. Lett. 85, no. 1, 147-158, doi: 10.1785/0220130091.

Faulkner, M., R. Clayton, T. Heaton, K. M. Chandy, M. Kohler, J. Bunn, R. Guy, A. Liu, M. Olson, M-H. Cheng, and A. Kraus (2014). Community sense and response systems: Your phone as quake detector, CACM 57, no. 7, doi: 10.1145/2622628.

Jones, L., R. Bernknopf, D. Cox, J. Goltz, K. Hudnut, D. Mileti, S. Perry, D. Ponti, M. Reichle, H. Selifson, K. Shoaf, J. Treiman, and A. Wein (2008). The ShakeOut Scenario, U.S. Geol. Surv. Open-File Rept. 2008-1150.

Kohler, M. D., R. Guy, J. Bunn, A. Massari, R. Clayton, T. Heaton, K. M. Chandy, H. Ebrahimian, and C. Dorn (2018). Community seismic network and localized earthquake situational awareness, 11th U.S. National Conference on Earthquake Engineering (11NCEE), Los Angeles, California, 25-29 June 2018.

Kong, Q., R. Allen, L. Schreier, and Y-W. Kwon (2016). MyShake: A smartphone seismic network for earthquake early warning and beyond, Sci. Adv. 2, e1501005, doi: 10.1126/sciadv.1501055.

Trifunac, M. (2008). Early history of the response spectrum method, Soil Dynam. Earthq. Eng. 28, 676-685, doi: 10.1016/j.soildyn.2007.10.014.

Wu, Y.-M., W.-T. Liang, H. Mittal, W.-A. Chao, C.-H. Lin, B. B.-S. Huang, and C.-M. Lin (2016). Performance of a low-cost earthquake early warning system (P-alert) during the $2016 \mathrm{ML}$ 6.4 Meinong (Taiwan) earthquake, Seismol. Res. Lett. 87, no. 5, 1050-1059, doi: $10.1785 / 0220160058$. 
Yong, A., E. Thompson, D. Wald, K. Knudsen, J. Odum, W. Stephenson, and S. Haefner (2016). Compilation of Vs30 data for the United States, U.S. Geol. Surv. Data Ser. 978, 8 p., doi: 10.3133/ds978.

\author{
Robert W. Clayton \\ Richard Guy \\ Thomas Heaton ${ }^{I}$ \\ Seismological Laboratory \\ California Institute of Technology \\ MS 252-21 \\ Pasadena, California 91125 U.S.A. \\ clay@gps.caltech.edu \\ Monica Kobler \\ Department of Mechanical and Civil Engineering \\ California Institute of Technology \\ Pasadena, California 91125 U.S.A.
}

Julian Bunn

Center for Data Driven Discovery

California Institute of Technology Pasadena, California 91125 U.S.A.

Mani Chandy

Engineering and Applied Science

California Institute of Technology Pasadena, California 91125 U.S.A.

${ }^{1}$ Also at Department of Mechanical and Civil Engineering, California Institute of Technology, Pasadena, California 91125 U.S.A. 